\title{
Role of advanced glycation end products (AGEs) and its receptor (RAGE)-mediated diabetic vascular complications
}

\author{
Diwesh Chawla $^{1 *}$ and Ashok Kumar Tripathi ${ }^{2}$ \\ ${ }^{1}$ Central Research Laboratory, Multi-disciplinary Research Unit, India \\ ${ }^{2}$ Department of Biochemistry, University College of Medical Sciences (University of Delhi) and G.T.B. Hospital, Dilshad Garden, Delhi-110095, India
}

\begin{abstract}
Diabetes Mellitus (DM) is one of the major health problems of the current century. It is associated with accelerating advanced glycation end products (AGEs) formation and accumulation in the circulating blood and various tissues. AGEs, also accelerate the expression of its receptor i.e. receptor for AGEs (RAGE) and plays a pivotal role in the development and progression of diabetic vascular complications through various mechanisms. Hyperglycemia mediated reactive oxygen species generation can induce oxidative stress through four major mechanisms including the polyol pathway, AGEs formation, activation of protein kinase $\mathrm{c}$ isoforms and the hexosamine pathway. Therapeutic interventions may improve the clinical course of patients having diabetes and its associated vascular complications by reducing the AGEs levels. This review summarizes the recent update on the role of AGE-RAGE mediated mechanisms in the development of diabetic vascular complications.
\end{abstract}

\section{Introduction}

Diabetes mellitus (DM) is one of the major epidemic disorders of the current century $[1,2]$. It is a group of metabolic disorders leading to defects in insulin secretion and action of insulin or both. Diabetes is influenced by a combination of both hereditary and environmental factors [3]. In the human body, blood glucose levels are controlled by a complex interaction of multiple chemicals and hormones, including insulin and glucagon. Insulin is one of the important peptide hormones produced from the beta cells of the pancreas that allows blood glucose to enter various cells of the body where it is oxidized to yield energy needed by the muscles and tissues to function [4]. Glucagon is also a peptide hormone, secreted from the alpha cells of the pancreas, which causes a rise in the blood glucose concentration. The effect of glucagon is opposite to that of insulin, which lowers the blood glucose concentration.

The global prevalence of DM in adults is increasing at an alarming rate. According to the recent update by the $8^{\text {th }}$ edition of the diabetes mellitus Atlas, it was reported that there are 425 million adults with DM in the world and it is estimated that there will be 693 million people with DM by the year 2045 [5]. This equates to approximately three new cases in every 10 seconds or almost 10 million per year. Diabetes caused 5.1 million deaths in 2013 and every six seconds a person dies from diabetes. Diabetes is rampant in Indian subcontinent. India is the $2^{\text {nd }}$ topmost country having the highest number of people with diabetes. The lack of adequate control in the consistently high level of glucose leads to the appearance of serious vascular complications.

\section{Vascular complications of diabetes}

Macrovascular and microvascular complications are the chronic vascular complications of diabetes, which are the major causes of morbidity and mortality (Figure 1). Diabetes, due to its increased prevalence has become the principal cause of blindness and end stage renal disease. About $30-45 \%$ of all diabetic subjects suffer from microvascular complications. Among microvascular complications,

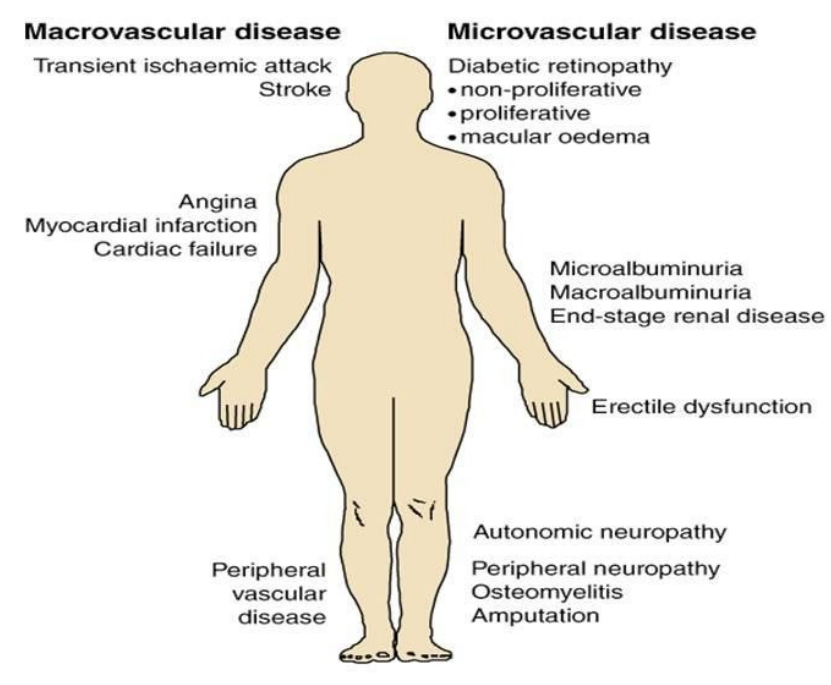

(Adapted from Bate et al, 2003. [6])

Figure 1. The major diabetic vascular complication

neuropathy, retinopathy and nephropathy were observed. The characteristic macrovascular complications include cardiovascular diseases. Patients with diabetes are at two to four times increased risk of coronary heart disease, cardiovascular disease and related deaths than those in the general population. Patients with diabetes are at four times

${ }^{\star}$ Correspondence to: Diwesh Chawla, Central Research Laboratory, Multidisciplinary Research Unit, India, E-mail: diweshchawla@yahoo.co.in

Key words: hyperglycemia, advanced glycation end products, vascular complications

Received: August 07, 2019; Accepted: September 19, 2019; Published: September 23, 2019 
higher risk of developing peripheral vascular disease (PVD) [6] Each of these organ specific vascular complications has its own unique, clinical and histologic features, but all are common with increasing duration of hyperglycemia and are driven by its downstream cellular signaling pathways [7].

The Diabetes Control and Complications Trial (DCCT) and United Kingdom Prospective Diabetes Study Trial (UKPDS) have clearly demonstrated the vital importance of intensive glycemic control in preventing the progression of diabetic complications $[8,9]$. Hyperglycemia inflicts cumulative long-term structural and functional changes in important macromolecules through advanced glycation end products (AGEs). Hyperglycemia induces a variety of metabolic changes, which includes activation of polyol pathway, activation of the diacylglycerol-protein kinase $c$, and increased oxidative stress. In this review, we summarize the recent updates on AGEs and the role of AGERAGE interaction-mediated various pathways which lead to diabetic vascular complications.

\section{Hyperglycemia mediated ROS generation}

Oxidative stress (OS) is defined as an imbalance between the reactive oxygen species (ROS) generation and the body's antioxidant defense system [10-12]. Various studies have evidenced that OS plays an important role in the pathogenesis of a wide range of human disorders such as diabetes, cancer, cardiovascular disorders, kidney diseases and neurodegenerative diseases [13-16]. Also the most important pathogenic role of OS in the initiation and development of diabetes associated complications has been determined. Free radical generation in hyperglycemic conditions may lead to OS in $\beta$-cells of the pancreas, which causes $\beta$-cell dysfunction and other long term complications of diabetes because of insulin secretion and /or its function impairment [17-20].

Under the normal physiological conditions, ROS generation may help in cell defense, hormone synthesis, signal transduction, transcription factor regulation and gene expression. While under pathological conditions; inflammation, tissue damage, fibrosis and $\beta$-cell death may occur [21,22]. There are four major mechanisms involved in the increased intracellular OS as a result of hyperglycemia, which includes the polyol pathway, advanced glycation end product formation, protein kinase c-diacyl glycerol pathway and hexosamine pathway (Figure 2). It has been reported that all of these pathways are activated by mitochondrial ROS overproduction. The effects of ROS generation can be modified by enzymatic or non-enzymatic antioxidants. Enzymatic antioxidant includes catalase, superoxide dismutase, nitric oxide synthase, glutathione peroxidase, glutathiones-transferase and nicotinamide adenine dinucleotide phosphate $(\mathrm{NADPH})$ oxidase. Non- enzymatic antioxidant includes vitamins, minerals, polyphenols, carotenoids and some other molecules [23,24].

The polyol pathway mainly focuses on the enzyme aldose reductase. Normally aldose reductase reduces toxic aldehydes in the cells to inactive alcohols, but under hyperglycemic condition, it utilizes NADPH and converts excessive intracellular glucose into the forms of sugar alcohols [15]. In healthier individuals, this pathway utilizes a very small fraction of the total glucose while in diabetic patients aldose reductase activated and induces increased conversion of glucose to sorbitol. After then, sorbitol is oxidized to fructose by enzyme sorbitol dehydrogenase with NAD+ as a cofactor [18]. Consumption of NADPH reduces glutathione reductase (GSH) activity as GSH is well known important scavenger of ROS [18,20,21]. Finally the process induces ROS generation and exacerbates intracellular OS.

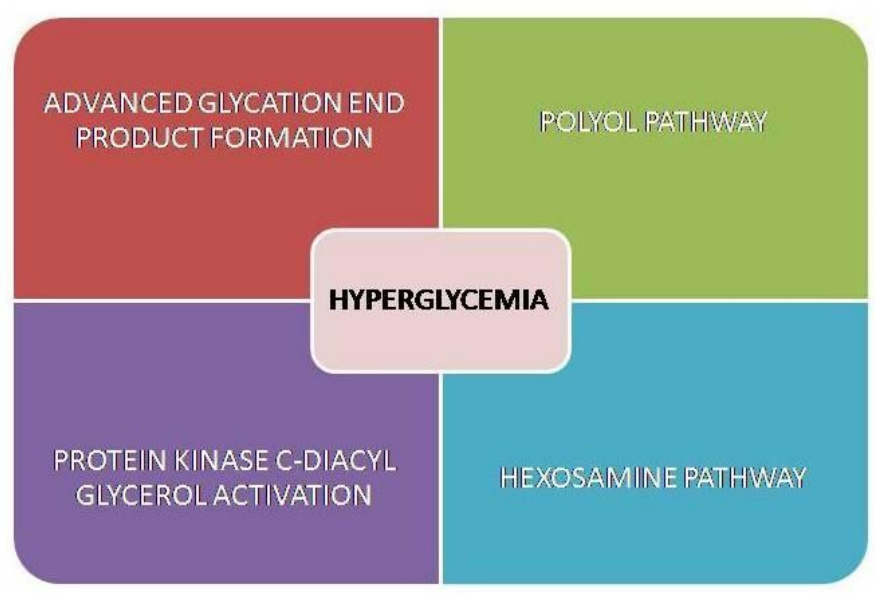

Figure 2. Hyperglycemia-mediated pathways

Hyperglycemia also induces overproduction of both the intracellular and extracellular AGEs [1]. Advanced glycation end product formation occurs as the result of glyoxal oxidation, 3-deoxyglucosome formation and fragmentation of glyceraldehyde3-phosphate into methyl glyoxal [15]. Cellular damage may occur due to intracellular production of AGE precursors through mainly three general mechanisms. Firstly, the functional intracellular proteins modification by AGEs may occur. After then abnormal interaction of extracellular matrix compounds which were modified by AGEs precursors with other matrix components and receptors such as integrin is observed. At last, finally the plasma proteins are modified by AGEs precursors binding to cell surface receptors such as receptor for AGEs (RAGE) or macrophage scavenger receptor [18,21]. This AGE-RAGE interaction may contribute to OS via induction of mitochondrial superoxide and cytosolic NADPH oxidase dependent mechanism, which activates multiple signals such as p21RAS, NF$\mathrm{kB}$, MAP kinase, TGF- $\beta$, vascular adhesion molecules, etc. This transcribes the number of pro-inflammatory genes and subsequently elicits vascular inflammation, over expression of endothelial growth factor, impaired fibrinolytic affinity, platelet aggregation, angiogenesis and thrombosis, thereby playing a central role in the pathogenesis of vascular complications in diabetes by enhancing the OS development [25-28]. These observations suggest that in diabetes, the increased AGEs production might alter glucose metabolism through direct attack on pancreatic insulin producing cells.

Protein kinase C (PKC) consists of at least eleven isoforms in mammalian tissues. Increased activation of PKC isoforms is the third most important pathway which induces tissue injury through hyperglycemia mediated ROS. Increased ROS generation inhibits activity of glycolytic enzyme glyceraldehydes-3-phosphate dehydrogenase, which leads to increase the level of diacyl glycerol (DAG) precursors [15]. Tissue phosphate also enhances the de novo synthesis of DAG from glucose. AGE- RAGE interaction also increases the activity of PKC isoforms. Hyperglycemia induced PKC activation may lead to over expression of plasminogen activator inhibitor-1 (PAI1) and activation of NF-kB [22]. This may lead to vascular damage via inflammation; increase the permeability of basement membrane thickening, angiogenesis and thrombotic vascular occlusion.

Under hyperglycemic condition, when the glucose level is higher inside the cell, most of the glucose is metabolized through glycolysis to glucose-6-phosphate, then to fructose-6-phosphate. Increasing the flux of fructose-6-phosphate into the hexosamine pathway may also 
contribute to pathogenesis of diabetic vascular complications [15]. Fructose-6-phosphate is diverted from glycolysis to provide glutamine fructose-6-phosphate aminotransferase (GFAT). After the conversion of fructose-6- phosphate to glucosamine-6-phosphate by GFAT, it is converted into UDP-N-acetyl glucosamine. It has been shown that hyperglycemia causes four folds increase in UDP-NAG, which induces hyperglycemia mediated activation of the PAI- 1 and TGF- $\beta 1[19,21]$. Under normal conditions, very small amount of glucose is metabolized through this pathway.

Therefore, it was believed that under hyperglycemic condition, mitochondria derived, OS leads to AGEs formation, DAG synthesis accelerated, PKC activation, sorbitol or fructose accumulation in the cells as a result of polyol pathway activation. These hypotheses suggest that hyperglycemia mediated OS play an important role in the pathogenesis of vascular disorders.

\section{Biochemistry of advanced glycation end products}

Hyperglycemia accelerates non-enzymatic reaction between the free amino groups of proteins and carbonyl groups of reducing sugars or other carbonyl compounds leading to enhanced formation of AGEs, also known as the Maillard reaction [25,26]. Advanced glycation end product formation is a complicated molecular process involving multistep reaction. A reducing sugar, such as glucose reacts nonenzymatically with the free amino group of protein to form an unstable compound, the Schiff base which undergoes a rearrangement reaction to form a more stable product known as Amadori product [27,28]. The Amadori adducts then very slowly undergo irreversible dehydration and condensation reactions leads to the formation of AGEs, which is yellowish brown material with the particular fluorescence. Advanced glycation end products are not produced only from glucose, but also from dicarbonyl compounds produced from auto-oxidation and the degradation products of glucose such as glyoxal, methylglyoxal and 3-deoxyglucosone or a-hydroxy aldehydes such as glyceraldehydes and glycoaldehyde. In addition, AGEs can also act as cross-linkers between proteins, resulting in the production of proteins-resistant aggregates [29].

Under chronic hyperglycemic condition, AGEs are actively produced and accumulate in the circulating blood and various tissues, resulting in vascular complications in diabetes. Furthermore, humans are also exposed to exogenous AGEs including tobacco, smoke, and diet. Food processing methods, such as prolonged heating and microwave cooking, can also accelerate the AGEs formation. As discussed earlier, the AGEs formation reaction also referred as browning reaction, this brown color change of food can be a measure of their AGE content. Over a dozen AGEs have been detected in tissues and can be divided into three categories: 1. Fluorescent cross-linking AGEs such as pentosidine and crossline. 2. Non-fluorescent cross-linking AGEs such as imidazolium dilysine cross-links, alkyl formyl glycosyl pyrrole (AFGP) cross-links and arginine-lysine imidazole (ALI) cross-links. 3. Non-cross- linking AGEs such as pyrraline and N-carboxymethyllysine (CML) [30]. The serum AGEs level was determined spectrofluorometrically at emission maximum $(440 \mathrm{~nm})$ upon excitation at $350 \mathrm{~nm}$ [26]. Briefly, serum was diluted 1:50 with phosphate buffer saline (PBS) $(\mathrm{pH}=7.4)$ and fluorescence intensity was expressed in arbitrary units (AU). Total serum AGEs were also determined by ELISA using commercial kits. Previously, we have reported that higher levels of circulating AGEs were observed in diabetic patients having vascular complications indicating that higher the serum AGEs level, higher the likelihood of development of vascular complication of diabetes [31-33]. Earlier gradual increase in serum AGEs-level have been reported with the severity of atherosclerosis in diabetic patients [34,35]. Kalusova et al determined AGEs spectrofluorometrically and found AGEs were about $23 \%$ higher in diabetic patients compared to healthy individuals [36]. In recent studies, AGEs level has been suggested to act as a predictor of CVD mortality and diabetic nephropathy [37-41].

Recent studies have evidenced that AGEs may be a key factor in the development of metabolic memory in diabetic vascular complications, because AGEs are produced and accumulated irreversibly in the body, depending on the degree of blood sugar regulation and duration $[42,43]$. AGEs interact with two main types of cell surface receptors viz, scavenger receptors, which remove and degrade AGEs and the one is receptor for AGEs (RAGE), which triggers specific cellular signaling responses on AGE binding.

\section{AGE-RAGE interaction-mediated pathways}

RAGE is one of the best characterized receptor which is responsible for AGEs related diabetic vascular complications, leads to activating the stress response leading to inflammation and cellular dysfunction [44-46]. RAGE is a $45 \mathrm{kD}$ transmembrane receptor of immunoglobin superfamily composed of 404 amino acid. It binds to many ligands apart from AGEs, such as high mobility group proteins B1, S100 calcium binding proteins including calgranulin, amyloid $\beta$ protein and amphotericin [47-51]. Apart from the full length, RAGE also available as soluble circulating isoform including sRAGE1/2/3, esRAGE (endogeneous soluble RAGE) and hRAGEsec (human RAGE secreted). A number of mechanisms have been reported that lead to the production of soluble proteins, alternative splicing of the mRNA to remove the transmembrane domain and the proteolytical cleavage from the cell surface. Various studies of RAGE have shown that sRAGE can be formed by both alternative splicing and proteolytic cleavage [52-54]. AGE-RAGE interaction activates signals through TGF- $\beta$, NF$\mathrm{kB}, \mathrm{MAP}$ kinase and NADPH oxidases, which induces the expression of E-selectin, vascular adhesion molecule-1, VEGF and various pro- inflammatory cytokines such as IL- $1 \beta$, IL- 6 and TNF- $\alpha$ (Figure 3 ). Under hyperglycemic conditions, activation of these signaling pathways is increased in vascular smooth muscle cells, leads to vascular fibrosis, calcification inflammation, prothrombotic effects and vascular damage processes like diabetic nephropathy, neuropathy, retinopathy and cardiovascular diseases. AGE-RAGE interaction mediated OS not only responsible for vascular disorders by activating renin angiotensin system (RAS) but also aggravate organ dysfunction, because RAS activation causes NADPH oxidase-mediated OS that may enhance RAGE expression and AGEs formation. In endothelial cells, AGERAGE interaction exacerbates the expression of $\mathrm{p} 22^{\text {phox }}$ and gp91 $91^{\text {phox }}$, which are the main components of NADPH oxidase, which promotes the production of ROS by activating the cell membrane transport of Rac family small GTPase1 (Rac1) to cause endothelial cell dysfunction [55-57]. Therefore, targeting the AGE-RAGE interaction has been considered as a potential therapeutic strategy to prevent or reduce vascular complications in diabetes.

\section{Therapeutic intervention of AGEs}

Inhibition of AGEs formation and attenuating the AGE-mediated effects may be considered as ideal candidates for pharmaceutical intervention in the amelioration of diabetic vascular complications. Therapies against the AGEs mediated effect can through diverse pathways, like inhibiting the production of Amadori products, decreasing AGE-RAGE interaction, detoxifying dicarbonyl intermediates and interrupting biochemical pathways that impact on 


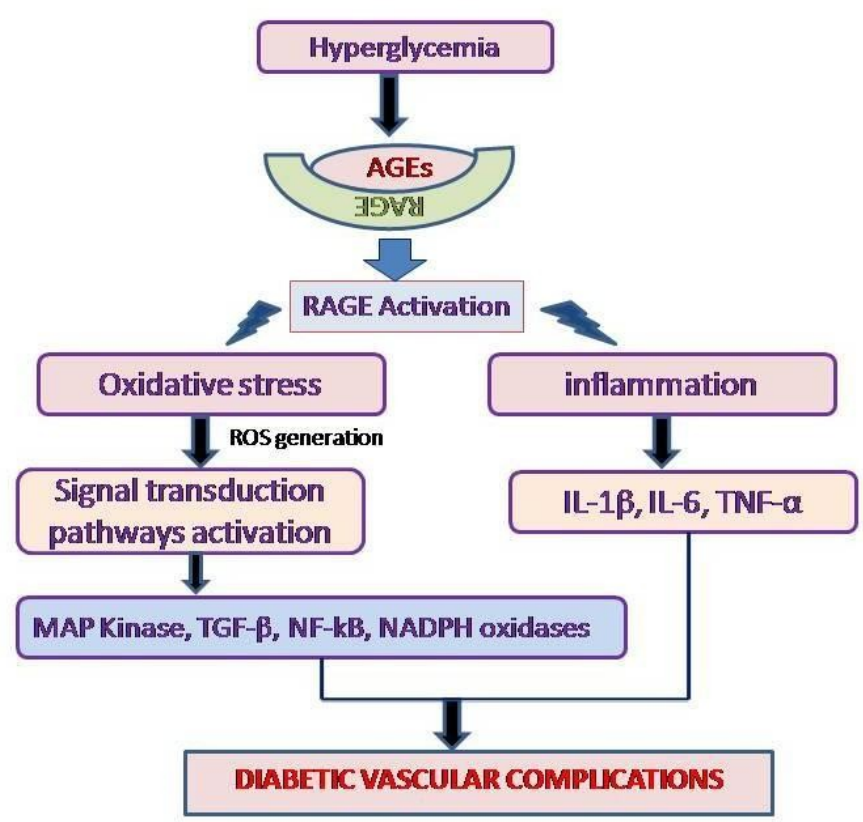

Figure 3. Suggested mechanism for AGE-RAGE mediated diabetic vascular complications

Table 1. Drugs/inhibitors which modulate AGEs formation

\begin{tabular}{|c|c|c|}
\hline Agents & Therapeutic Effects & References \\
\hline Aminoguanidine & $\begin{array}{l}\text { Rapidly reacts with } \alpha, \beta \text { dicarbonyl compounds such as } \\
\text { methyl glyoxal, glyoxal and 3-deoxyglucosone to prevent } \\
\text { AGEs formation. }\end{array}$ & [58-60] \\
\hline Ramipril & $\begin{array}{l}\text { An angiotensin converting enzyme inhibitor, inhibit the } \\
\text { expression of inflammatory markers by inhibiting signal } \\
\text { transduction by AGEs. }\end{array}$ & [61] \\
\hline $\begin{array}{l}\text { N-acetyl } \\
\text { cystamine }\end{array}$ & $\begin{array}{l}\text { AGE-RAGE mediated ROS generation which induces } \\
\text { mesengial cell hypertrophy and fibronectin synthesis has } \\
\text { been inhibited }\end{array}$ & [62-66] \\
\hline Telmisartan & $\begin{array}{l}\text { An angiotensin receptor blocker, inhibit the expression of } \\
\text { oxidative stress markers by inhibiting signal transduction } \\
\text { by AGEs. }\end{array}$ & {$[67,68]$} \\
\hline Pravastatin & $\begin{array}{l}\text { Inhibit tubular damage in diabetic nephropathy in tubular } \\
\text { cells and attenuate AGEs-induced apoptosis. }\end{array}$ & [69] \\
\hline Atorvastatin & Inhibit AGEs formation & {$[70]$} \\
\hline Curcumin & Inhibits AGE-mediated NF-kB and AP-1 activity. & [71-73] \\
\hline Linagliptin & Inhibit AGE-RAGE mediated ROS generation. & {$[74]$} \\
\hline Resveratrol & $\begin{array}{l}\text { Reduces the risk of cardiovascular disease in diabetes } \\
\text { by regulating } \\
\text { and cytokines. }\end{array}$ & {$[75,76]$} \\
\hline ALT-711 & AGE crosslink breaker & [77] \\
\hline Rosiglitazone & $\begin{array}{l}\text { Reduces the expression of RAGE on the myocardium } \\
\text { and attenuate cardiac fibrosis and ventricular diastolic } \\
\text { function }\end{array}$ & [78] \\
\hline Exendin-4 & $\begin{array}{l}\text { Inhibit AGE-RAGE interaction mediated damage in } \\
\text { tubular cells to attenuate the development and progression } \\
\text { of diabetic nephropathy. }\end{array}$ & [79] \\
\hline Alagebrium & AGE crosslink breaker & [61] \\
\hline
\end{tabular}

AGEs level. Several drugs are known to modulate AGEs; few of them with their therapeutic effects were shown in Table 1.

\section{Conclusion}

There is an increase in the level of AGEs formation under hyperglycemic conditions. These AGEs formation and accumulation may be one of the contributing factors in the development of diabetic vascular complications. The possibility of reducing glycation of protein or circulating AGEs or targeting AGE-RAGE mediated mechanisms may be an approachable target of delaying or preventing the onset of diabetic complications. Various compounds are under investigation for their possible therapeutic intervention. Finally, the use of AGEs as biomarkers/predictors of diabetic complications may be helpful to reduce health problems in diabetic patients.

\section{References}

1. Gray SP, Jandeleit-Dahm K (2014) The pathobiology of diabetic vascular complicationscardiovascular and kidney disease. JMM 92: 441-452.

2. Banerjee M, Vats $P$ (2014) Reactive metabolites and antioxidant gene polymorphisms in Type 2 diabetes mellitus. Redox Biology 2: 170-177.

3. Góth L, Nagy T (2012) Acatalasemia and diabetes mellitus. Arch Biochem Biophys 525: 195-200. [Crossref]

4. Harris M, Zimmet P (1997) Classification of diabetes mellitus and other categories of glucose intolerance. Alberti K, Zimmet P, Defronzo R, editors. International textbook of diabetes mellitus. Second Edition. Chichester: John Wiley and Sons Ltd, pp9: -23.

5. International diabetes federation (2017) IDF Diabetes Atlas, 8th edn. Brussels, Belgium: International diabetes federation, 2017. http://www.diabetesatlas.org.

6. Bate KL, Jerums G (2003) 3: Preventing complications of diabetes. Med J Aust 179: 498-503. [Crossref]

7. Brownlee M (2005) The pathobiology of diabetic complications: A unifying mechanism. Diabetes 54: 1615-1625.

8. Writing team for the diabetes control and complications trial/epidemiology of diabetes interventions and complications research group (2003) Sustained effect of intensive treatment of type 1 diabetes mellitus on development and progression of diabetic nephropathy: The epidemiology of diabetes interventions and complications (EDIC) study. JAMA 290: 2159-2167.

9. Holman RR, Paul SK, Bethel MA, Matthews DR, Neil HA (2008) 10-year follow-up of intensive glucose control in type 2 diabetes. $N$ Engl J Med 359: 1577-1589. [Crossref]

10. Rashid K, Sinha K, Sil PC (2013) An update on oxidative stress-mediated organ pathophysiology. Food Chem Toxicol 62: 584-600

11. Fatehi-Hassanabad Z, Chan CB, Furman BL (2010) Reactive oxygen species and endothelial function in diabetes. Eur J Pharmacol 636: 8-17.

12. Crawford A, Fassett RG, Geraghty DP, Kunde DA, Ball MJ, et al. (2012) Relationships between single nucleotide polymorphisms of antioxidant enzymes and disease. Gene 501: 89-103.

13. Zweier JL, Chen CA, Druhan LJ (2011) S-glutathionylation reshapes our understanding of endothelial nitric oxide synthase uncoupling and nitric oxide/reactive oxygen species-mediated signaling. Antioxid Redox Signal 14: 1769-1775.

14. Picu A, Petcu L, Ştefan S, Mitu M, Lixandru D, et al. (2017) Markers of oxidative stress and antioxidant defense in romanian patients with type 2 diabetes mellitus and obesity. Molecules 22: E714.

15. Giacco F, Brownlee M (2010) Oxidative stress and diabetic complications. Circ Res 107: 1058-1070. [Crossref]

16. Crawford A, Fassett RG, Coombes JS, Kunde DA, Ahuja KD, et al. (2011) Glutathione peroxidase, superoxide dismutase and catalase genotypes and activities and the progression of chronic kidney disease. Nephrol Dial Transplant 26: 2806-2813.

17. Da Costa LA, Garcia-Bailo B, Badawi A, El-Sohemy A (2012) Genetic determinants of dietary antioxidant status. Prog Mol Biol Transl Sci 108: 179-200.

18. Rahimi R, Nikfar S, Larijani B, Abdollahi M (2005) A review on the role of antioxidants in the management of diabetes and its complications. Biomed Pharmacother 59: $365-$ 373. [Crossref]

19. Karunakaran U, Park KG (2013) A systematic review of oxidative stress and safety of antioxidants in diabetes: focus on islets and their defense. Diabetes Metab J 37: 106-112.

20. Saeidnia S, Abdollahi M (2013) Toxicological and pharmacological concerns on oxidative stress and related diseases. Toxicol Appl Pharmacol 273: 442-455.

21. Madonna R, De Caterina R (2011) Cellular and molecular mechanisms of vascular injury in diabetes-- part I: pathways of vascular disease in diabetes. Vascul Pharmacol 54: 68-74.

22. Tabatabaei-Malazy O, Larijani B, Abdollahi M (2012) A systematic review of in vitro studies conducted on effect of herbal products on secretion of insulin from langerhans islets. J Pharm Pharm Sci 15: 447-466. 
23. Johansen JS, Harris AK, Rychly DJ, Ergul A (2005) Oxidative stress and the use of antioxidants in diabetes: Linking basic science to clinical practice. Cardiovasc Diabetol 4: 5 .

24. Tabatabaei-Malazy O, Nikfar S, Larijani B, Abdollahi M (2014) Influence of ascorbic acid supplementation on type 2 diabetes mellitus in observational and randomized controlled trials; a systematic review with meta-analysis. J Pharm Pharm Sci 17: 554582 .

25. Semba RD, Sun K, Schwartz AV, Varadhan R, Harris TB, et al. (2015) Serum carboxymethyl-lysine, an advanced glycation end product, is associated with arterial stiffness in older adults. J Hypertens 33: 797-803

26. Brownlee M (1992) Glycation products and the pathogenesis of diabetic complications. Diabetes Care 15: 1835-1843.

27. John WG, Lamb EJ (1993) The Maillard or browning reaction in diabetes. Eye (Lond) 7: 230-237. [Crossref]

28. Monnier VM (1990) Non-enzymatic glycosylation, the Maillard reaction and the aging process. J Gerontol 45: B105-B11.

29. Lapolla A, Piarulli F, Sartore G, Ceriello A, Ragazzi E, et al. (2007) Advanced glycation end products and antioxidant status in type 2 diabetic patients with and without peripheral artery disease. Diabetes Care 30: 670-676.

30. Neelofar K, Ahmad J (2017) An overview of in vitro and in vivo glycation of albumin: A potential disease marker in diabetes mellitus. Glycoconj J 34: 575-584

31. Chawla D, Bansal S, Banerjee BD, Madhu SV, Kalra OP, et al. (2014) Role of advanced glycation end product (AGE)-induced receptor (RAGE) expression in diabetic vascular complications. Microvasc Res 95: 1-6.

32. Bansal S, Chawla D, Banerjee BD, Madhu SV, Tripathi AK (2013) Association of RAGE gene polymorphism with circulating AGEs level and paraoxonase activity in relation to macro-vascular complications in Indian type 2 diabetes mellitus patients. Gene 526: 325-330.

33. Bansal S, Chawla D, Siddarth M, Banerjee BD, Madhu SV, et al. (2013) A study on serum advanced glycation end products and its association with oxidative stress and paraoxonase activity in type 2 diabetic patients with vascular complications. Clin Biochem 46: 109-114.

34. Nin JW, Jorsal A, Ferreira I, Schalkwijk CG, Prins MH, et al. (2011) Higher plasma levels of advanced glycation end products are associated with incident cardiovascular disease and all-cause mortality in type 1 diabetes. Diabetes Care 34: 442-447.

35. Yoshida N, Okumura K, Aso Y (2005) High serum serum pentosidine concentrations are associated with increased arterial stiffness and thickness in patients with type 2 diabetes. Metabolism 54: 345-350.

36. Kalousova M, Krha J, Zima T (2002) Advanced glycation end-products and advanced oxidation protein products in patients with diabetes mellitus. Physiol Res 51: 597-504.

37. Martín-Timón I, Sevillano-Collantes C, Segura-Galindo A, Del Cañizo-Gómez FJ (2014) Type 2 diabetes and cardiovascular disease: Have all risk factors the same strength? World J Diabetes 5: 444-470.

38. Anavekar NS, Gans DJ, Berl T, Rohde RD, Cooper W, et al. (2004) Predictors of cardiovascular events in patients with type 2 diabetic nephropathy and hypertension: a case for albuminuria. Kidney Int Suppl 92: S50-S55.

39. Kerkeni M, Saïdi A, Bouzidi H, Letaief A, Ben Yahia S, et al. (2013) Pentosidine as a biomarker for microvascular complications in type 2 diabetic patients. Diab Vasc Dis Res 10: 239-245.

40. Kilhovd BK, Juutilainen A, Lehto S, Ronnemaa T, Torjesen PA, et al. (2007) Increased serum levels of advanced glycation endproducts predict total, cardiovascular and coronary mortality in women with type 2 diabetes: a population-based 18 year followup study. Diabetologia 50: 1409-1417.

41. Genuth S, Sun W, Cleary P, Sell DR, Dahms W, et al. (2005) Glycation and carboxymethyllysine levels in skin collagen predict the risk of future 10-year progression of diabetic retinopathy and nephropathy in the diabetes control and complications trial and epidemiology of diabetes interventions and complications participants with type 1 diabetes. Diabetes 54: 3103-3111.

42. Koska J, Saremi A, Howell S, Bahn G, De Courten B, et al. (2018) Advanced glycation end products, oxidation products, and incident cardiovascular events in patients with type 2 diabetes. Diabetes Care 41: 570-576.

43. Rhee SY, Kim YS (2018) The role of advanced glycation end products in diabetic vascular complications. Diabetes Metab J 42: 188-195.

44. Herold K, Moser B, Chen Y, Zeng S, Yan SF, et al. (2007) Receptor for advanced glycation end products (RAGE) in a dash to the rescue: inflammatory signals gone awry in the primal response to stress. J Leukoc Biol 82: 204-212.
45. Kalea AZ, Schmidt AM, Hudson BI (2009) RAGE: A novel biological and genetic marker for vascular disease. Clinical Science 116: 621-637.

46. Hudson BI, Kalea AZ, Del Mar Arriero M, Harja E, Boulanger E, et al. (2008) Interaction of the RAGE cytoplasmic domain with diaphanous-1 is required for ligandstimulated cellular migration through activation of Rac1 and Cdc42. J Biol Chem 283 : 34457-34468

47. Srikrishna G, Huttunen HJ, Johansson L, Weigle B, Yamaguchi Y, et al. (2002) $\mathrm{N}$-Glycans on the receptor for advanced glycation end products influence amphoterin binding and neurite outgrowth. $J$ Neurochem 80: 998-1008.

48. Al-Mesallamy HO, Hammad LN, El-Mamoun TA, Khalil BM (2011) Role of advanced glycation end product receptors in the pathogenesis of diabetic retinopathy. J Diabetes Complications 25: 168-174.

49. Huebschmann AG, Regensteiner JG, Vlassara H, Reusch JE (2006) Diabetes and advanced glycoxidation end products. Diabetes Care 29: 1420-1432. [Crossref]

50. Wada R, Yagihashi S (2005) Role of advanced glycation end products and their receptors in development of diabetic neuropathy. Ann N Y Acad Sci 1043: 598-604.

51. Neeper M, Schmidt AM, Brett J, Yan SD, Wang F, et al. (1992) Cloning and expression of a cell surface receptor for advanced glycosylation end products of proteins. J Biol Chem 267: 14998-15004.

52. Schlueter C, Hauke S, Flohr AM, Rogalla P, Bullerdie J (2003) Tissue-specific expression patterns of the RAGE receptor and its soluble forms: a result of regulated alternative splicing? Biochim Biophys Acta 1630: 1-6.

53. Yonekura H, Yamamoto Y, Sakurai S, Petrova RG, Abedin MJ, et al. (2003) Novel splice variants of the receptor for advanced glycation end-products expressed in human vascular endothelial cells and pericytes, and their putative roles in diabetes-induced vascular injury. Biochem J 370: 1097-1109.

54. Park IH, Yeon SI, Youn JH, Choi JE, Sasaki N, et al. (2004) Expression of a novel secreted splice variant of the receptor for advanced glycation end products (RAGE) in human brain astrocytes and peripheral blood mononuclear cells. Mol Immunol 40: 1203-1211.

55. Yamagishi S, Nakamura N, Suematsu M, Kaseda K, Matsui T (2015) Advanced glycation end products: a molecular target for vascular complications in diabetes. Mol Med 21 Suppl 1: S32-S40.

56. Bucala R, Tracey KJ, Cerami A (1991) Advanced glycosylation products quench nitric oxide and mediate defective endothelium-dependent vasodilatation in experimental diabetes. J Clin Invest 87: 432-438.

57. Xu B, Ji Y, Yao K, Cao YX, Ferro A (2005) Inhibition of human endothelial cell nitric oxide synthesis by advanced glycation end-products but not glucose: relevance to diabetes. Clin Sci (Lond) 109: 439-446.

58. Thornalley PJ (2003) Use of aminoguanidine (Pimagedine) to prevent the formation of advanced glycation endproducts. Arch Biochem Biophys 419: 31-40.

59. Zhao W, Tilton RG, Corbett JA, McDaniel ML, Misko TP, et al. (1996) Experimental allergic encephalomyelitis in the rat is inhibited by aminoguanidine, an inhibitor of nitric oxide synthase. J Neuroimmunol 64: 123-133.

60. Fu MX, Wells-Knecht KJ, Blackledge JA, Lyons TJ, Thorpe SR, et al. (1994) Glycation, glycoxidation, and cross-linking of collagen by glucose. Kinetics, mechanism, and inhibition of late stages of the Maillard reaction. Diabetes 43: 676-683.

61. Coughlan MT, Thallas-Bonke V, Pete J, Long DM, Gasser A, et al. (2007) Combination therapy with the advanced glycation end product cross-link breaker, alagebrium, and angiotensin converting enzyme inhibitors in diabetes: synergy or redundancy? Endocrinology 148: 886-895.

62. Zafarullah M, Li WQ, Sylvester J, Ahmad M (2003) Molecular mechanisms of N-acetylcysteine actions. Cell Mol Life Sci 60: 6-20. [Crossref]

63. Nogueira GB, Punaro GR, Oliveira CS, Maciel FR, Fernandes TO, et al. (2018) Nacetylcysteine protects against diabetic nephropathy through control of oxidative and nitrosative stress by recovery of nitric oxide in rats. Nitric Oxide 78: 22-31.

64. Thieme K, Da Silva KS, Fabre NT, Catanozi S, Monteiro MB, et al. (2016) N-Acety cysteine attenuated the deleterious effects of advanced glycation end-products on the kidney of non-diabetic rats. Cell Physiol Biochem 40: 608-620.

65. Dludla PV, Dias SC, Obonye N, Johnson R, Louw J, et al. (2018) A systematic review on the protective effect of $\mathrm{N}$-acetyl cysteine against diabetes-associated cardiovascular complications. Am J Cardiovasc Drugs 18: 283-298.

66. Dekhuijzen PNR (2004) Antioxidant properties of N-acetylcysteine: their relevance in relation to chronic obstructive pulmonary disease. Eur Respir J 23: 629-636. 
67. Kikuchi K, Tancharoen S, Ito T, Morimoto-Yamashita Y, Miura N, et al. (2013) Potential of the angiotensin receptor blockers (ARBs) telmisartan, irbesartan, and candesartan for inhibiting the HMGB1/RAGE axis in prevention and acute treatment of stroke. Int J Mol Sci 14: 18899-18924.

68. Yamagishi S, Nakamura K, Matsui T (2009) Regulation of advanced glycation end product (AGE)- receptor (RAGE) system by PPAR-gamma agonists and its implication in cardiovascular disease. Pharmacol Res 60: 174-178.

69. Ishibashi Y, Yamagishi S, Matsui T, Ohta K, Tanoue R, et al. (2012) Pravastatin inhibits advanced glycation end products (AGEs)-induced proximal tubular cell apoptosis and injury by reducing receptor for AGEs (RAGE) level. Metabolism 61: 1067-1072.

70. Zhou F, Tan Y, Chen XH, Wu FL, Yang DJ, et al. (2018) Atorvastatin improves plaque stability in diabetic atherosclerosis through the RAGE pathway. Eur Rev Med Pharmacol Sci 22: 1142-1149.

71. Basnet P, Skalko-Basnet N (2011) Curcumin: an anti-inflammatory molecule from a curry spice on the path to cancer treatment. Molecules 16: 4567-4598.

72. Zhang DW, Fu M, Gao SH, Liu JL (2013) Curcumin and diabetes: a systematic review. Evid Based Complement Alternat Med 2013: 636053.

73. Karimian MS, Pirro M, Majeed M, Sahebkar A (2017) Curcumin as a natural regulator of monocyte chemoattractant protein-1. Cytokine Growth Factor Rev 33: 55-63.
74. Nakashima S, Matsui T, Takeuchi M, Yamagishi SI (2014) Linagliptin blocks renal damage in type 1 diabetic rats by suppressing advanced glycation end productsreceptor axis. Horm Metab Res 46: 717-721.

75. Arcanjo NMO, Luna C, Madruga MS, Estévez M (2018) Antioxidant and pro-oxidant actions of resveratrol on human serum albumin in the presence of toxic diabetes metabolites: Glyoxal and methyl-glyoxal. Biochim Biophys Acta 1862: 1938-1947.

76. Olas B, Wachowicz B, Saluk-Juszczak J, Zieliński T (2002) Effect of resveratrol, a natural polyphenolic compound, on platelet activation induced by endotoxin or thrombin. Thromb Res 107: 141-145. [Crossref]

77. Forbes JM, Yee LT, Thallas V, Lassila M, Candido R, et al. (2004) Advanced glycation end product interventions reduce diabetes-accelerated atherosclerosis. Diabete 53: 1813-1823.

78. Ihm SH, Chang K, Kim HY, Baek SH, Youn HJ, et al. (2010) Peroxisome proliferatoractivated receptor-gamma activation attenuates cardiac fibrosis in type 2 diabetic rats: the effect of rosiglitazone on myocardial expression of receptor for advanced glycation end products and of connective tissue growth factor. Basic Res Cardiol 105: 399-407.

79. Ojima A, Ishibashi Y, Matsui T, Maeda S, Nishino Y, et al. (2013) Glucagon-like peptide-1 receptor agonist inhibits asymmetric dimethylarginine generation in the kidney of streptozotocin-induced diabetic rats by blocking advanced glycation end product-induced protein arginine methyltranferase-1 expression. Am J Pathol 182 132-141. [Crossref]

Copyright: $\odot 2019$ Chawla D. This is an open-access article distributed under the terms of the Creative Commons Attribution License, which permits unrestricted use, distribution, and reproduction in any medium, provided the original author and source are credited. 